\title{
Chapter 8. Understanding supply chain dynamics via simulation
}

\author{
Severine Strohhecker, Stephen M. Disney and Mohamed M. Naim
}

\begin{abstract}
The aim of this chapter is to outline the generic aspects of a simulation study in understanding and then improving on the dynamic behaviour of a supply chain. The chapter describes the various types of simulation that are available to supply chain designers. The chapter focuses on one particular type of simulation, namely Systems Dynamics. The principals of a simulation study are explained via a case study in which a simulation-based business diagnostic is undertaken in a low-value fit-out construction supply chain. The purpose of the business diagnostic is to investigate the dynamic performance of several re-engineering strategies. The dynamics of the strategies are assessed via a range of performance measures. The current supply chain suffered from a large number of merchants and protracted lead-times. The impact of replacing the 16 merchants with a single supplier who provided "kits" of components to the building site is considered. The benefits from an implementation of a supply chain wide IT system are also investigated. Aligning the supply chains planning buckets and ensuring that everyone in the supply chain works to the same "beat" is examined. Overlaying each of these scenarios is a simulation-based investigation of the influence of mistrust and information sharing. The simulation study allowed us to confirm current practice, predict future dynamic performance, identify improvement opportunities, and validate previously known supply chain management strategies in our construction industry case study.
\end{abstract}




\section{Introduction}

Simulation is a technique which replicates a real-world situation, usually by means of a simplified model representation, and its dynamic behaviour reproduced. The model is used to understand cause and effect relationships leading to insights as to why certain behaviours occur. Form such an analysis various alternative scenarios to improve behaviour may be tested. The advantage of simulation is that the scenario may be tested at minimum risk to the real-world situation - either due to the fact that the scenario may actually lead to a detriment to performance or may be too costly to implement in the real-world without full testing beforehand.

Simulation is a well established form of analysis in construction engineering and management. Previous research in construction simulation has focussed on the on-site physical processes (e.g AbouRizk and Halpin, 1990, Martinez and Ioannou, 1999) and with a strong emphasis on discrete (e.g. González et al., 2006) or discrete event simulation (e.g. Nassara et al., 2003, Kamata \& Martinez, in press). Less well researched the role of simulation in modelling construction supply chains and their associated material, information and resource flows. This chapter has to substantive aims. The first is to introduce the reader the concept of simulation as applied to construction supply chains. The second aim is to show the application of System Dynamics simulation in the context of testing supply chain management principles, as outlined in Chapters 9-14. More specifically the chapter investigates the material flow management principles as defined in Chapter 24, namely, centralisation of supply, the total cycle time reduction and improved relationships between the trading partners, can be tested via simulation modelling. We will analyse if these principles can be used to improve dynamic performance. To achieve this, we will endeavour to 'teach by example', giving an overview of the application of a simulation study to a low-value fit-out housing supply chain. We start with an explanation of a 
generic supply chain modelling methodology and review the types of dynamic modelling and simulation techniques available. We then describe a low-value fit-out supply chain where a number of specific problem areas, or 'hot spots', have been identified.

This is followed by a presentation and evaluation of possible supply chain management solutions to cool these 'hot spots'. The first solution considered is the centralisation of supply by turning away from regional procurement with multiple merchants. The second solution consists of sharing customer information across the supply chain and finally the third step considers the synchronisation of lead-times between trading partners.

The performance is assessed based on the data collected during an in-depth business diagnostic of the supply chain and simulation is used to assess its dynamic performance. Finally the results are summarised and the "best" performing scenario is highlighted.

\section{Modelling and simulation}

Whilst Chapter 2 provides a construction-specific perspective of modelling, this Section, following an overview of the generic principles for modelling supply chains, focuses specifically on simulation as applied to the material, information and resource flows that constitute a housing supply chain. Modelling and simulation should be considered as part of an extensive structured method to the reengineering of supply chains. Naim and Towill (1994) have proposed a framework to analyse the dynamic properties of supply chains. This complements the work of other researchers and practitioners in the field by integrating 'soft', or qualitative (e.g. Checkland and Scholes, 1990) and 'hard', or quantitative (e.g. Disney and Towill, 2003) approaches. The framework, shown in Figure 1, aims to develop valid models of business processes that constitute the supply chain so as to optimise the total flow of information, 
materials and other resources such and people, money and machines, amongst others.
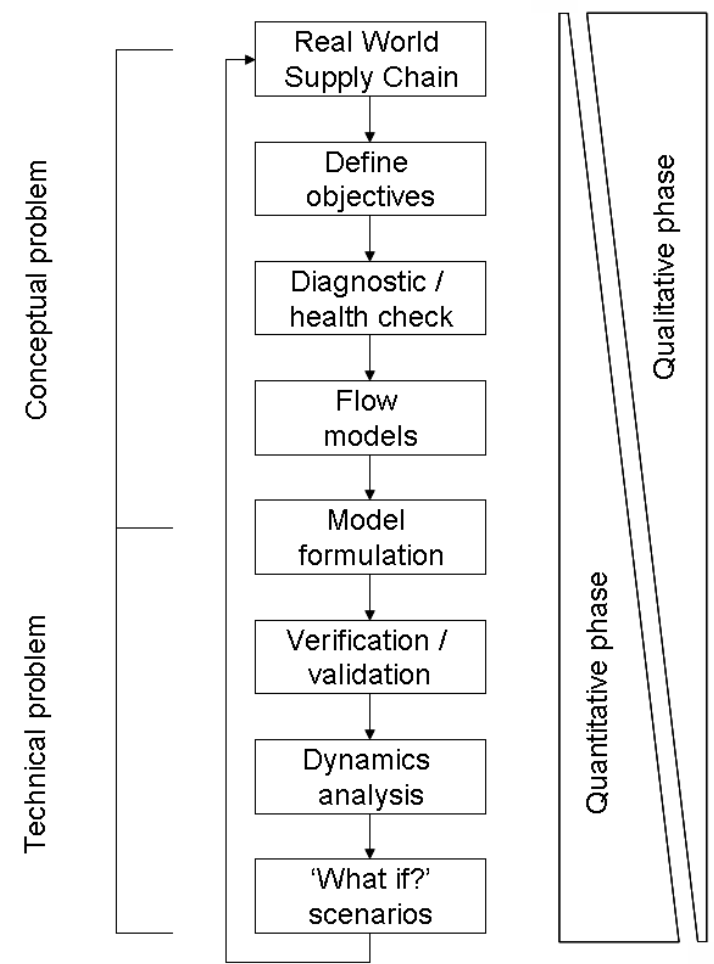

\section{Figure 1 - Modelling and simulation framework for supply chain design (Naim and Towill, 1994)}

The framework consists of two discrete but overlapping phases. The qualitative phase is consists of acquiring sufficient knowledge to understand the current structure and operation of a supply chain. The quantitative phase develops and analyses and numerical models with simulation. The two phases overlap in varying proportions as modelling becomes more quantitative. Therefore, the skills required of the team re-engineering the supply chain will vary according to which stage of the framework is reached.

The initial conceptual stage of systems analysis aids in defining the boundaries of the problem 
and interfaces within the system under study. During this stage a flow analysis is undertaken. This flow analysis typically takes the form of value stream maps or process charts and helps to evaluate the time delays and logistics constraints involved in both value adding and non-value adding activities undertaken. The flow analysis also provides a means to uncover the cause and effect relationships present in the supply chain. At this stage of the simulation process, supply chain diagnostic methods that have been applied in many sectors may be used, such as the Quick Scan (QS) in the automotive industry (Lewis et al., 1998, Naim et al., 2002), and a QS adaptation in the construction industry, named the Terrain Scanning Methodology (TSM) (Barker et al., 2000). As in the flow analysis, such diagnostic methods may exploit questionnaires, interviews and archival data in order to obtain a rich picture of the current situation, its main problems and their possible causes.

The information obtained from the flow analysis can support the development of suitable conceptual models. Two conceptual modelling tools are used in this chapter. These are rich pictures (Checkland, 1981, 1990) and causal loop diagrams (Wolstenholme, 1990). Both of them represent the causal relationships between those variables driving the dynamic behaviour of the supply chain.

As the nature of the flows becomes known, the conceptual model is converted into a simulation or an analytical form. As we will see later, there are software packages, such as Stella/iThink ${ }^{\circledR}$ and Vensim ${ }^{\circledR}$, that allow the direct input of a causal loop diagram and the generation of numerical expressions to represent relationships between variables.

The first stage of the quantitative phase is the selection of possible modelling techniques for analysing the supply chain. A model is a representation of reality and the study of which is easier 
to study than the real system. Simulation models may used for; produce new results, verify results, or demonstrate relationships (Kramer and de Smit, 1977). Naim et al (2004) identify various types of modelling techniques within the context of supply chain management:

(a) Management games: these are typically table top games that re-enact a management decision in the supply chain. The dynamic behaviour resulting from the decisions taken by the players can be demonstrated and then discussed. These games may even be incorporated into computer software or embedded into web pages to facilitate the decision-making experience. Games are limited in the sense that, in general, nothing can be rigorously proved from the game in itself. However they do have the advantage of allowing participants to experience specific learning outcomes for themselves. The notable supply chain management game is the Beer Game (Sterman, 1989), which has been extended or computerised by various authors including van Ackere et al (1993), and Lambrecht and Dejonckheere (1999a and b).

(b) Statistical investigations: they usually involve the analysis of difference equations via conditional expectation and is often highly mathematical. This type of contribution typically provides statistical insights about the impact of demand properties such as standard deviation and auto-correlation, and supply chain properties, such as lead-times and information paths, on inventory costs and capacity requirements. Statistical methods are often used to quantify performance of real situations. Recent significant contributions of this type include Lee et al. (2000) and Chen et al. (2000).

(c) Continuous control theory techniques: these have also been used in the supply chain management field. Typically they have been developed for the analysis of physical hardware systems by electrical and mechanical engineers. However, Simon (1952) described how to use linear deterministic control theory for production and inventory control. Axsäter (1985) presents 
a useful review paper of early work, summarising the advantages and limitations of the field.

He concludes that control theory "illustrates extremely well dynamical effects and feedback", but cannot incorporate sequencing and lot-sizing issues. Continuous control theory suffers from the fact that some scheduling and ordering scenarios are inherently discrete and the continuous representation of pure time delays is mathematically complicated (but not impossible, Warburton and Disney, 2007).

(d) Discrete control theory: is a digital version of continuous control theory and is a very powerful way of investigating sampled data systems (i.e. a scheduling and ordering systems and computer system which are inherently discrete). Vassian (1955), inspired by Simon's work in the continuous domain, studied a production-scheduling algorithm using discrete control theory. Burns and Sivazlian (1978) considered a four level traditional supply chain using z-transforms. Popplewell and Bonney (1988) have investigated MRP systems. Disney (2001) has been using discrete control theory to investigate Vendor Managed Inventory supply chains.

(e) Classical operations research (OR) and management science: at about the same time as the seminal work of Simon (1952) and Vassian (1955), this separate but parallel strand of research established a dynamic programming approach to the inventory control problem. Arrow (2002) provides a review of the search for the optimal inventory policy. While not actually investigating structural dynamics, this approach aims to establish optimal policies for inventory control. For example, the assumptions may be concerned with the cost structure, demand pattern, lead-times and planning horizons. Towill et al. (2003) have undertaken a detailed comparison of the control theory and OR approach to Decision Support System (DSS) design for managing supply chain dynamics.

(f) Simulation and system dynamics: was advocated by Forrester $(1958,1961)$ as a method of 
investigating the dynamical effects in large non-linear systems as a means of avoiding having to resort to complicated mathematical or control theory based models (Edghill and Towill, 1989). Previous work using simulation is very prolific and includes (but it is by no means limited to) Forrester $(1958,1961)$, and Coyle (1982), who studied traditional supply chain structures, Cachon and Fisher (1997) and Waller et al. (1999) who studied Vendor Managed Inventory supply chain structures.

It is the latter modelling method that we will concentrate on in this chapter. Naylor et al. (1966) define simulation as "a numerical technique for conducting experiments on a digital computer, which involves certain types of mathematical and logical models that describe the behaviour of a system over extended periods of real time."

Hoover and Perry (1989) and Law and Kelton (1991) identify three dimensions of simulation:

(a) Static vs. dynamic: static simulation is a representation of a situation at a particular time (or a representation based on averages), such as the linear programming or Economic Order Quantity techniques, whereas dynamic simulation represents the system as it evolves over time. The main advantages of dynamic simulation can be summarised as:

- It incorporates the impact of time into the performance evaluation (Bowersox et al., 1986).

- It is flexible, especially in comparison with analytical tools, details can be included which could not be possible with analytical models (Hoover and Perry, 1989).

- The researcher has control over the other variables in comparison with the real system (Johnsson, 1992). 
(b) Deterministic vs. stochastic: the lack of any random components makes a simulation model deterministic, i.e. the outcome is determined once the model relationships and initial stages have been defined, whereas the outcome of stochastic models are random variables.

(c) Continuous vs. discrete: in continuous simulation, time is assumed to pass continuously i.e. events can happen at any point in time. In discrete simulation, the state variables change instantaneously only at separate points in time. This means that the system states can change only at a countable number of points in time. These points in time may be based upon a clock, in which simulation proceeds in uniform steps in time) or upon events, in which simulation has steps that are governed by the events that occur along the simulation, such as those that begin or end.

System Dynamics simulation is dynamic, makes use of both deterministic and stochastic changes and is a clock-driven discrete simulation, but one which attempts to minimise the uniform steps to as to approximate to a continuous tie simulation.

\section{An example of system dynamics in a house building supply chain}

\section{The low-value fit-out supply chain current state}

This case study description is the outcome of an interventionist action research programme with a housing developer in the United Kingdom. The case study follows the framework given in Figure 1. The real world supply chain investigated was a low-value fit-out supply chain. The purpose of the research was to investigate the dynamic performance of several re-engineering strategies. The programme involved a team of researchers undertaking the TSM diagnostic to ascertain the current state followed by the secondment of one member of the research team to the collaborating organisation. The secondee worked with the change management team responsible for developing and implementing the organisation's supply chain strategy. The secondee was 
responsible for the model development involving interviews with key personnel in the orgaisation, with the whole team working together in scenario development.

The main sub-systems of a house can be divided into three categories, the house shell, the highvalue fit-out and the low-value fit-out. By house shell, we mean the foundations, interior and exterior walls and roof. High value fit out is concerned with the items such as the bathroom suite and kitchen. The low value fit-out is concerned with items such as doors, skirting, electricity and plumbing. For the ease of explaining the principals of the simulation approach this chapter will focus on the case of the low-value fit-out.

Typically for bulk or low-value items such as skirting boards, steel lintels, door linings, doors, hinges, etc., the supply process is carried out via multiple merchants and manufacturers on a regional basis. Thus, these products are purchased from a wide range of suppliers based on a minimum cost.

Figure 2 illustrates a rich picture representation of the flows of a house building supply chain. The focus is placed upon the major issues of planning and control for the supply chain. The products are ordered by the regional buyer and called off by the site manager when required. The products are then delivered to site in a stock yard from which the products are selected, sorted and moved to the exact construction location.

Seven "hot spots" have been identified during the research and have been reported in Naim and Barlow (2003). Hot spots are the main problem areas from a supply chain perspective and are represented by the symbol that looks like a "bomb". They are summarised in Table 1 . These "hot spots" cover a wide range of issues from the lack of customer information to a high level of waste and a lack of supply chain integration. These "hot spots" can be identified by their symptoms, such as poor supplier delivery performance, poor availability of material on-site, or 
unsatisfied customers. However what needs to be tackled are the root causes. These may be such things as the adversarial approach to trading, regional buying arrangements, purchase decisions based solely on price, or even the lack of strategy for utilising the information available in planning activities.

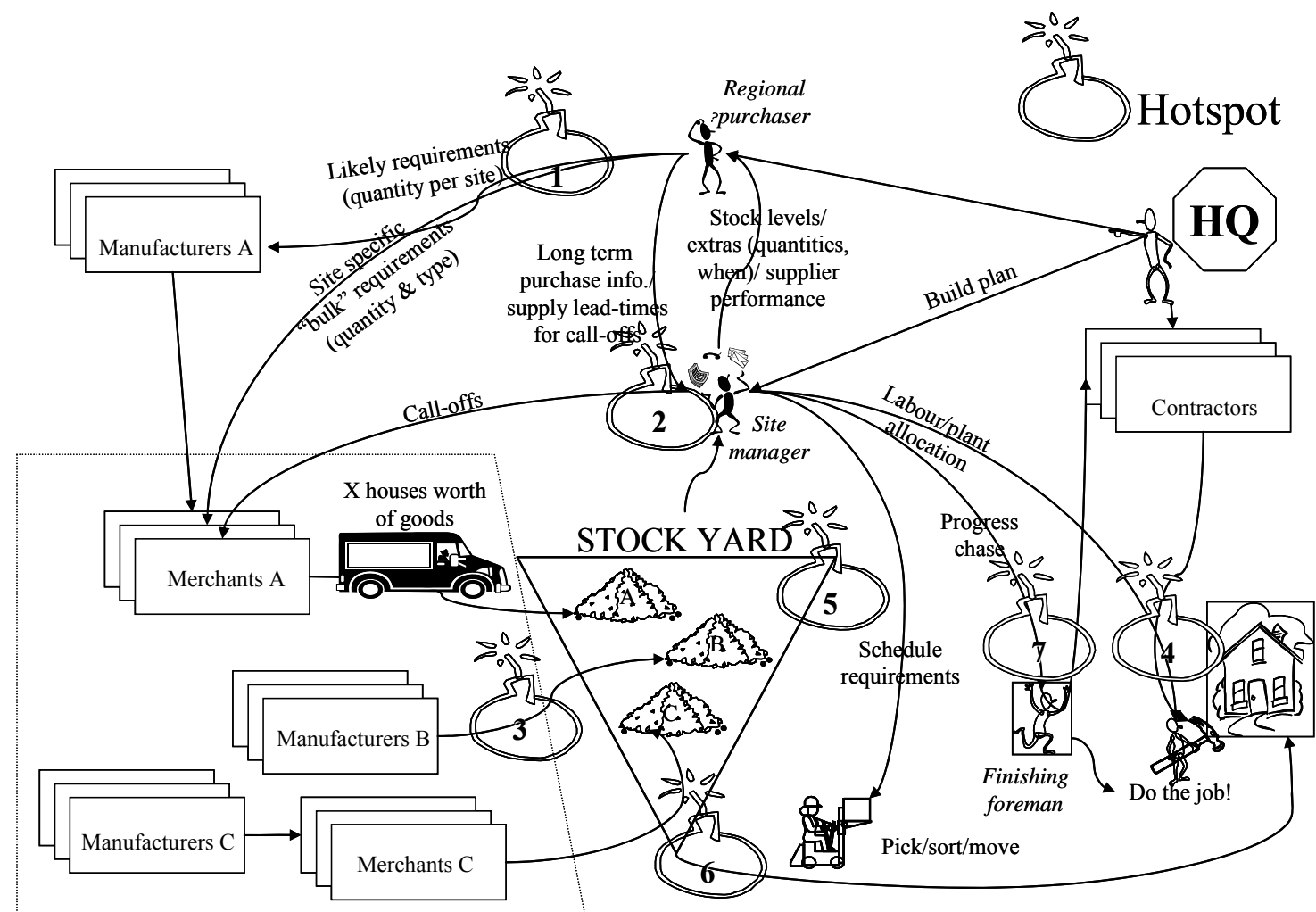

Figure 2 - Rich picture representation of the traditional supply chain for a generic house building supply chain (Naim and Barlow, 2003)

For simplicity of understanding and analysis, the traditional low-value fit-out supply chain can be simplified, as shown in Figure 3. Only two manufacturers have been considered, a door manufacturer (A) and a skirting boards manufacturer (B). The lead times were established according to data collected in the business diagnostic case study. The site manager has to wait a minimum of 7 days after the order is placed by the regional buyers, before he can call off the material from the merchants. It usually takes 14 days for the merchant to fulfil that order but only 
Strohhecker, S., Disney, S.M. and Naim, M.M., (2008), "Understanding supply chain dynamics via simulation", Chapter 9 in "Construction Supply Chain Management Handbook”, Edited by O'Brien, W.J., Formoso, C.T., Vrijhoef, R. and London, K.A., CRC Press, Boca Raton, USA, 30pp. ISBN 978-1-4200-4745-5.

\begin{tabular}{|c|c|c|}
\hline Hot Spot & Root causes & Symptoms \\
\hline $\begin{array}{l}\text { Hot spot 1: Little use of } \\
\text { market knowledge for } \\
\text { buying and calling off the } \\
\text { material }\end{array}$ & $\begin{array}{l}\text { - Regionally based buying } \\
\text { agreements } \\
\text { - Purchase based on price } \\
\text { - No time scale guarantee for } \\
\text { actual delivery }\end{array}$ & $\begin{array}{l}\text { Suppliers have little } \\
\text { visibility of long-term } \\
\text { market requirements }\end{array}$ \\
\hline $\begin{array}{l}\text { Hot spot 2: Lack of supply } \\
\text { chain integration }\end{array}$ & $\begin{array}{c}\text { - The site manager needs to } \\
\text { co-ordinate a large amount of } \\
\text { people and tasks } \\
\text { - He holds a considerable } \\
\text { amount of information } \\
\text { - No clear strategy of how best } \\
\text { to utilise the information }\end{array}$ & $\begin{array}{l}\text { Very poor information } \\
\text { transfer and use across the } \\
\text { supply chain }\end{array}$ \\
\hline $\begin{array}{l}\text { Hot spot 3: No time } \\
\text { compression strategy }\end{array}$ & $\begin{array}{c}\text { - Lack of supplier } \\
\text { development and } \\
\text { adversarial relationships } \\
\text { - Volatile short-term call off } \\
\text { information from the site } \\
\text { - Late changes in site } \\
\text { requirements }\end{array}$ & $\begin{array}{l}\text { Poor supplier delivery } \\
\text { performance }\end{array}$ \\
\hline $\begin{array}{l}\text { Hot spot 4: Inability to } \\
\text { rapidly re-configure }\end{array}$ & $\begin{array}{l}\text { - No medium term planning } \\
\text { horizon given to sub- } \\
\text { contractors } \\
\text { - High work uncertainty } \\
\text { pushes subcontractors } \\
\text { to commit themselves to } \\
\text { several tasks }\end{array}$ & $\begin{array}{l}\text { Poor availability of } \\
\text { contractors on-site }\end{array}$ \\
\hline $\begin{array}{l}\text { Hot spot } 5 \text { and } 6 \text { : } \\
\text { Excessive muda, or waste }\end{array}$ & $\begin{array}{l}\text { - High level of stock on-site to } \\
\text { buffer against uncertainties } \\
\text { - No designated stocking area } \\
\text { and proper recording } \\
\text { mechanism lead to damage, } \\
\text { mislaying or theft of material }\end{array}$ & $\begin{array}{l}\text { Poor availability of material } \\
\text { on-site }\end{array}$ \\
\hline $\begin{array}{l}\text { Hot spot 7: Excessive human } \\
\text { resource }\end{array}$ & $\begin{array}{l}\text { - Above problems lead to the } \\
\text { need for a finishing foreman } \\
\text { to chase material, chase labour } \\
\text { and assign rework and snag } \\
\text { list }\end{array}$ & $\begin{array}{l}\text { Dissatisfied customer (poor } \\
\text { total value) }\end{array}$ \\
\hline
\end{tabular}

Table 1 - Summary of specific "hot spots" in the traditional supply chain of low-value fitout material (based on the generic concept from Naim and Barlow, 2003)

different regional buyers. However, even within the same regions a multiple (generally 2 to 3 per site) number of merchants are used. 


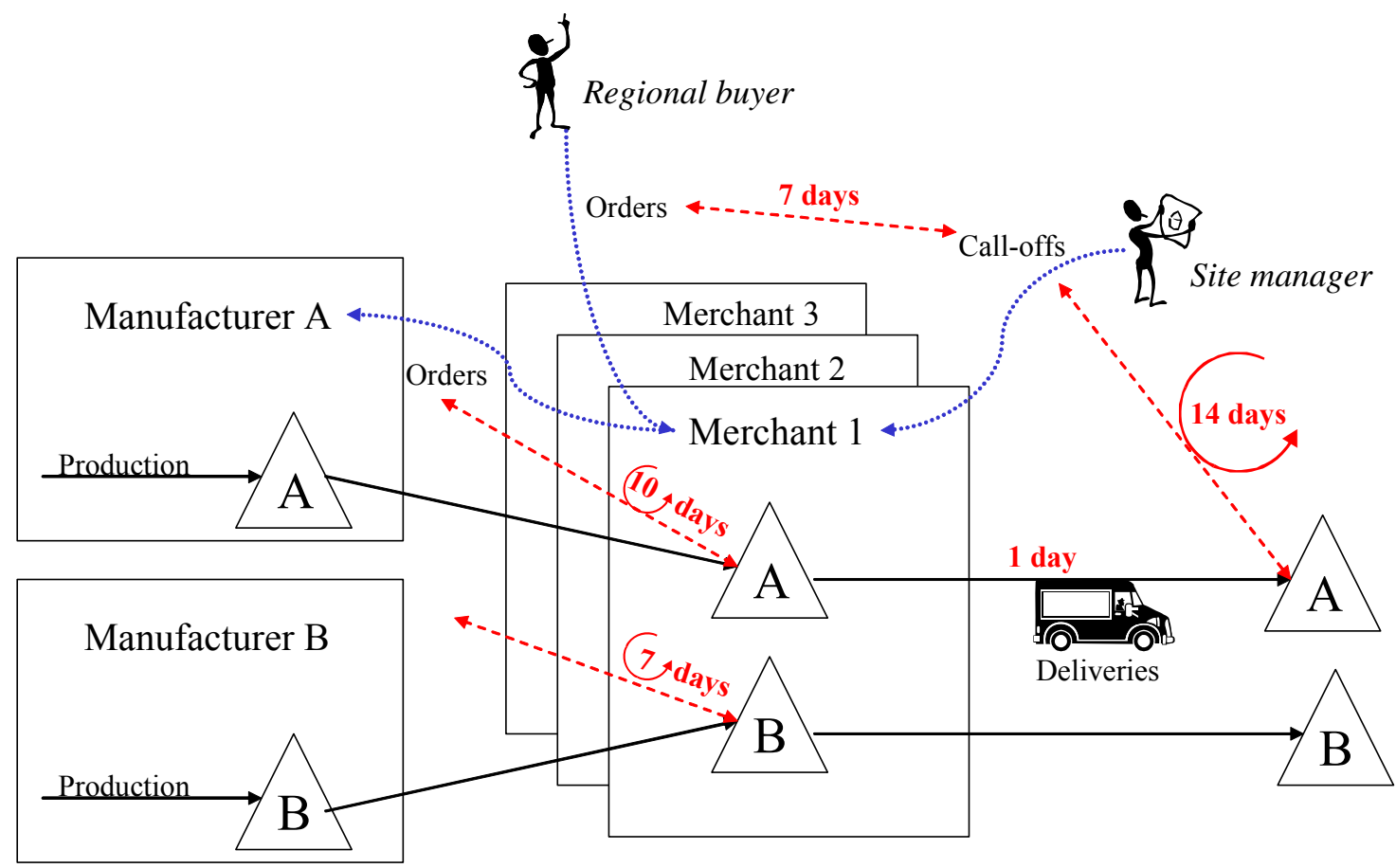

Note: A represents doors and B skirting boards

Figure 3 - Traditional low-value fit-out supply chain

The replenishment of doors requires a 10-day lead-time while the replenishment of skirting board requires a 7-day lead-time. Furthermore, as mentioned before, the relationships between the companies tend to be adversarial. Home builders' satisfaction is generally low with regards the availability of material, as highlighted in "hot spots" 5 and 6. Customer satisfaction is also perceived as low, as identified in "hot spot" 7.

Predictably, on-costs and lead-times are also high. "On-costs" are unnecessary costs associated with the highly variable workload. Some materials, believed to be in the stock yard, might have been misplaced, stolen or damaged and replacement material will need to be ordered, causing delays the construction process. Furthermore, the unreliability of deliveries also makes it difficult to predict the finishing date. 


\section{Re-engineering the low-value fit-out supply chain}

This section describes three alternatives developed by the change management team for improving the performance of the low-value fit-out supply chain in relation to the traditional practices. The first alternative is to move away from local supply through multiple merchants, and use one national distributor. The second alternative focuses on improving the information flow across the supply chain. Finally, the third alternative is concerned with the synchronisation of lead-times across the supply chain.

\section{Merchant's integration}

"Hot spots" 3, 5, and 6 highlighted poor supplier delivery performance and lack of availability of materials on-site. One possible solution is to use only a single merchant, which will be called "the Kitter". This strategy is based upon a future supply chain state our case company was just about to achieve. There are different reasons behind this strategy. First, regional buyers usually select merchants based on price. Therefore many different merchants are used for the procurement of low-value fit-out materials. Instead, one single merchant is used in this strategy. This means that regional buyers do not have to search for the cheapest merchant available but simply place their orders to the single supplier. This is only possible because the Kitter has been vertically integrated and it is therefore part of Home Builder. The Kitter/ Home Builder believed that the vertical integration would mean lower prices.

Second, only using the Kitter to procure all material needed on a nation-wide basis increases its buying power. It also allows the Kitter to negotiate directly with most manufacturers, as the buying quantities are larger. The approximate turnover for a large merchant is $£ 250$ million, $£ 40$ million for the Kitter, and $£ 30$ million for a small to medium sized merchant. The builder’s 
merchants sector has been consolidating recently as large merchants have greater buying power (Agapiou et al., 1998; Anon, 1998). The Kitter is dealing with 26 suppliers, of which 18 are manufacturers. If a third of the materials are still purchased from the merchants it is due to the reluctance of the manufacturers to deal directly with a rather small customer compared to the large merchants. As mentioned above, the prices are also guaranteed to be lower through the Kitter. For example a specific type of skirting board would be sold at $£ 0.45$ per metre while a standard merchant would sell it for $£ 0.53$ per metre, or in other words, the Kitter would be $15 \%$ cheaper. For a specific architrave, the Kitter would sell at $£ 1.13$ per metre against $£ 1.30$ per metre from a merchant, which is $13 \%$ cheaper.

Third, not only are all the low-value fit-out materials bought from the Kitter, but they are also sent in packs. All materials for a low-value fit-out are distributed in 7 packs for masonry construction and only 4 packs for timber frame construction. Each pack is specifically aimed at different stages of construction of a house. For example, in one pack, items such as external doors, skirting, architrave, doorstop, internal doors, hinges and door latches and locks are packed together for a specific house type. The idea behind the use of packs is to reduce waste on-site arising from damaged, mislaid, and stolen material in the stockyard, making possible to reduce stocks on-site. Furthermore, it also reduces on-site deliveries as one delivery of packs could correspond to up to 6 deliveries from the individual merchants. Finally, it assures a faster assembly process as the whole kit is available at once and therefore all the parts needed for one part of the construction process are readily available. This concept of packs is similar to kitting which has a long history in the electronic industry. Bozer and McGinnis (1984) define a kit as "a specific collection of components and/or subassemblies which, with other kits (if any), support one or more assembly operations for a given product". The use of such a system is appropriate 
for products with numerous parts or high-value components or for the quality assurance reasons, Johansson (1991).

Fourth, using the Kitter allows a reduction from 14 to 7 days for delivery lead-time from the call off. This 7-day lead-time is made up of 4 days to prepare the packs and 3 days for the delivery of the packs, as shown in Figure 4. Furthermore, as Home Builder has vertically integrated the Kitter, the stock control responsibility is kept within Home Builder. This will improve upon the merchants poor service level.

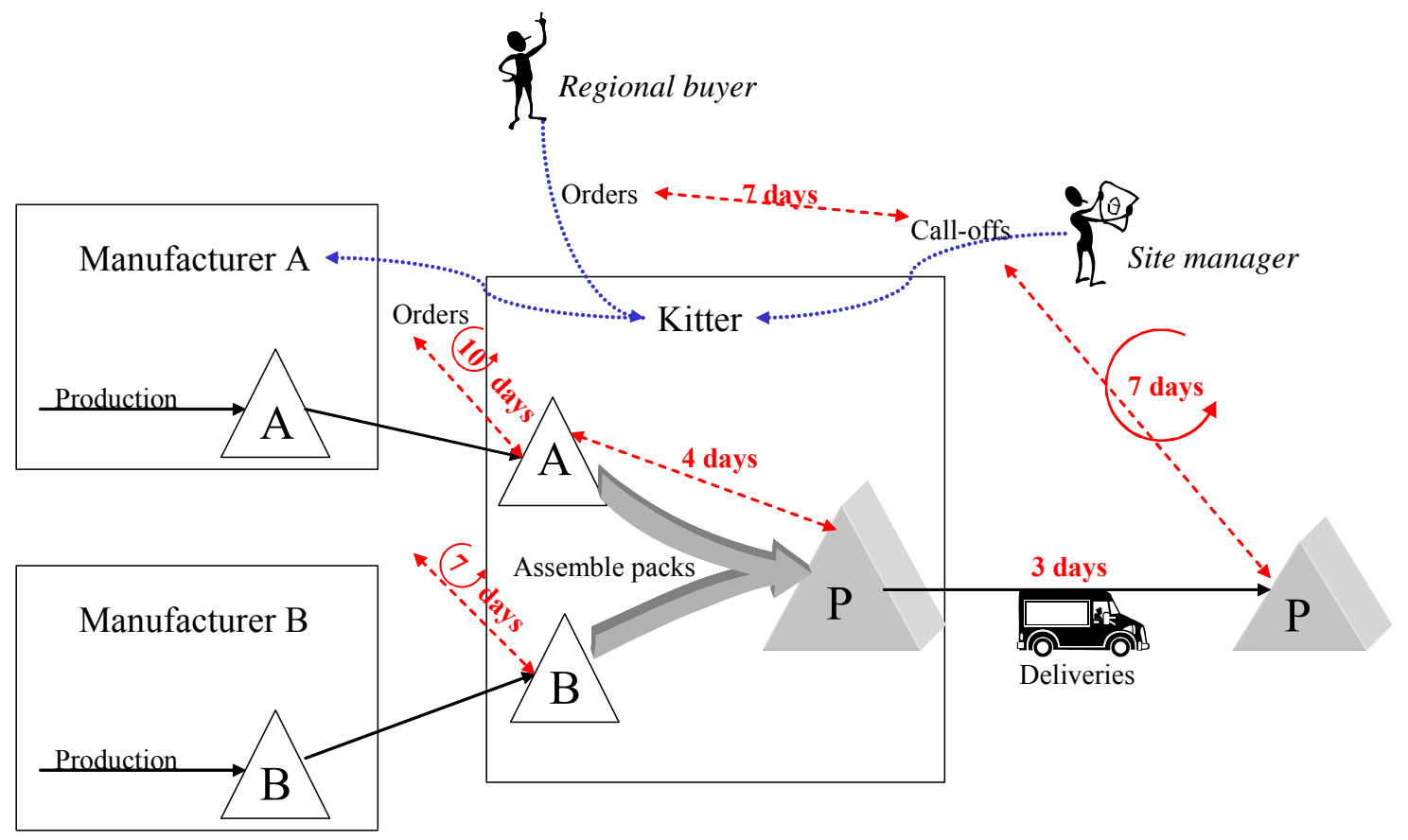

Note: A represents doors and B skirting boards

Figure 4 - Low-value fit-out supply chain using Kitter

\section{Information flow integration}

Improvements in the information flow need to be made in order to address the "hot spots" 1, 2 and 3: little visibility of long term market requirements by suppliers, very poor information transfer and use across the supply chain, and poor supplier delivery performance. Among the 
root causes of those three "hot spots" are the insufficient amount and availability of information. One way to share information with several different organisations in a timely and accurate fashion is to use information technology (IT). In our case company the Home Builder has decided to use the SAP/R3 system in the near future. The new information system would be accessible by site managers, regional buyers, the Kitter and the manufacturers. The construction schedule will be posted on the system and up-dated as required. Therefore all the organisations involved will have access to accurate information on the site progress. Furthermore, the ordering and call-off processes will also be carried out by managers with the support of an information system.

It is envisioned that the total order cycle time will be reduced to 5 days. One day advance notice before calling off the packs will suffice for the Kitter. This is based on the assumptions that the house design is standardised and that the Kitter is in possession of the drawings. Therefore, the packs could be assembled within three days. Finally, as shown in Figure 5, the delivery lead-time will be cut down to one day. This is already happening in most cases, the three days presented in the previous section being a buffer rather than a necessity. This planning time buffer is common in the industry (Wegelius-Lehtonen and Pahkala, 1998).

\section{Synchronisation}

The last SCM configuration that has been investigated is the synchronisation of lead-times in the supply chain (Stevens, 1989; Sabath, 1995; Towill, 2000), whereby the lead-times are established to ensure a continuous flow o material through the supply chain without any queues. This scenario was specifically developed by the change management team with the collaboration of the procurement manager from the Kitter. With the Kitter working at full capacity and the SAP system fully implemented, lead-times could be further reduced to achieve a total order 


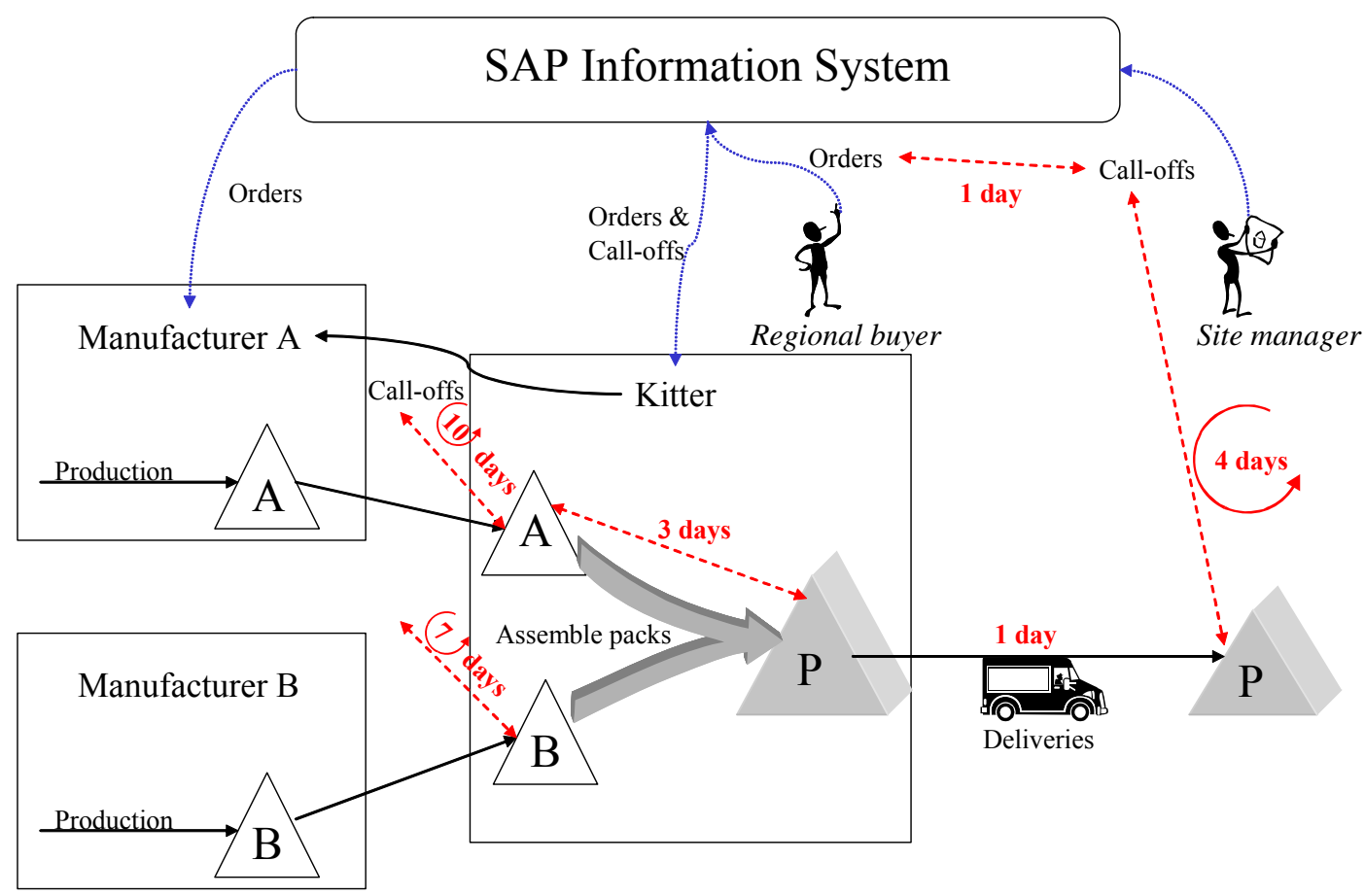

Note: A represents doors and B skirting boards

\section{Figure 5 - Low-value fit-out supply chain with information integration}

cycle time of three days, as shown in Figure 6. Only one day is required for Pack assembly as the personnel have gone through their learning curve and house designs have been standardised. Thus, variations from one pack to another are limited. It will still be necessary to allow one day for the transfer of the packs to site. As the relationship with the manufacturers shifts from being adversarial to being more collaborative, the manufacturers will have access to up-to-date information from the IT system and the total order cycle time will be reduced to 3 days. This means that the different organisations in the supply chain will work on the same 3-day order cycle time and will therefore be synchronised. 


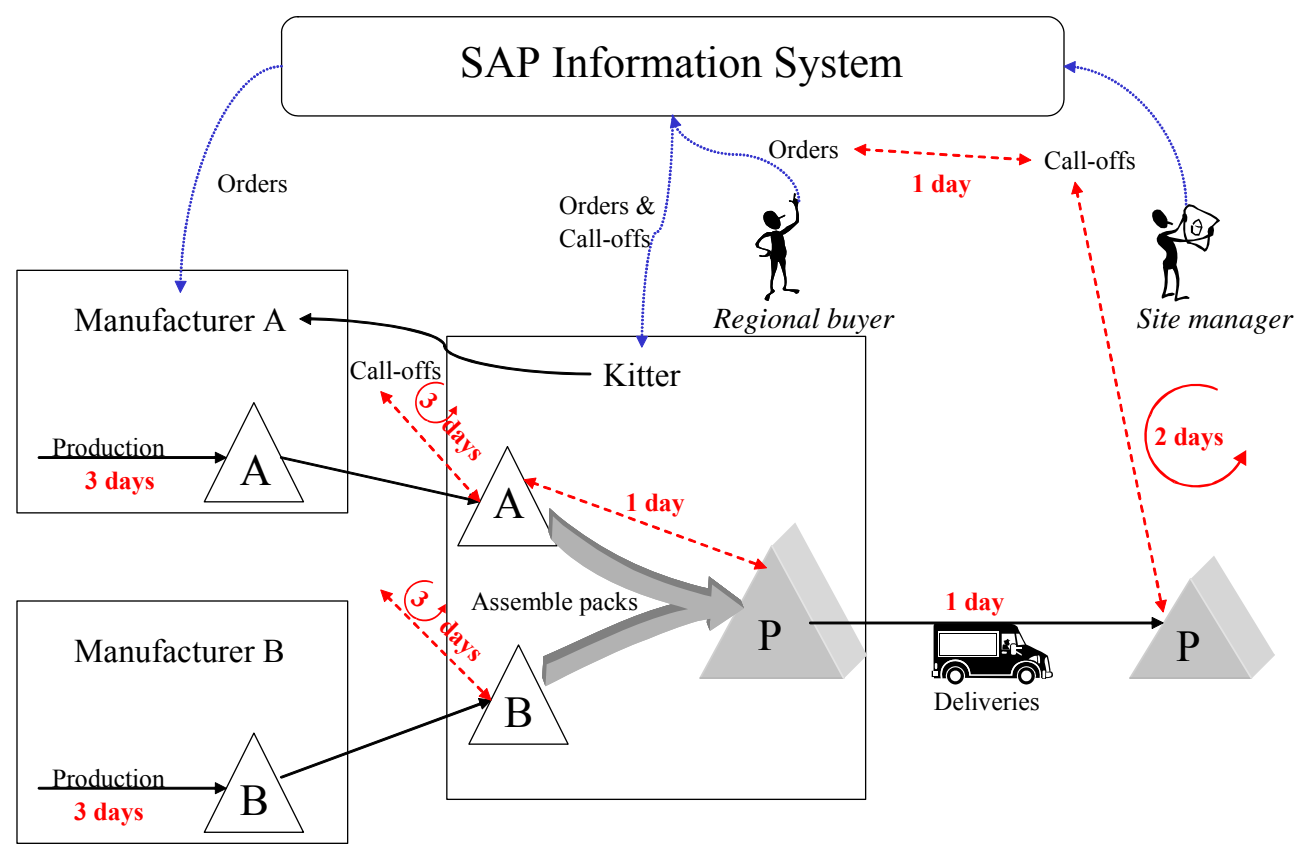

Note: A represents doors and B skirting boards

Figure 6 Synchronised low-value fit-out supply chain

\section{Summary of the re-engineering scenarios}

Table 2 summarises the four scenarios for the low-value fit-out supply chain in terms of supply chain structure, the involvement of each agent, the type of innovation introduced and the total order cycle time.

\section{Implications on supply chain dynamics}

The simulation model was used to test if one point of control with one stocking point, improved information flow, reduction of lead-times and synchronisation can improve the dynamic performance of the supply chain. This section will present the simulation model, the simulated scenarios, and the simulation results. 
Strohhecker, S., Disney, S.M. and Naim, M.M., (2008), "Understanding supply chain dynamics via simulation", Chapter 9 in "Construction Supply Chain Management Handbook”, Edited by O'Brien, W.J., Formoso, C.T., Vrijhoef, R. and London, K.A., CRC Press, Boca Raton, USA, 30pp. ISBN 978-1-4200-4745-5.

\begin{tabular}{|c|c|c|c|c|}
\hline Scenarios & Baseline & Kitter & $\begin{array}{l}\text { Integrated } \\
\text { information }\end{array}$ & Synchronised \\
\hline $\begin{array}{l}\text { Supply chain } \\
\text { structure }\end{array}$ & $\begin{array}{c}\text { Developer, } \\
\text { multiple } \\
\text { merchants, } \\
\text { manufacturers }\end{array}$ & \multicolumn{3}{|c|}{ Developer, single merchant, manufacturers } \\
\hline $\begin{array}{l}\text { Role of the } \\
\text { developer }\end{array}$ & $\begin{array}{l}\text { Order from } \\
\text { merchants }\end{array}$ & \multicolumn{3}{|c|}{ Order from Kitter } \\
\hline $\begin{array}{c}\text { Role of } \\
\text { Merchants / } \\
\text { Kitter }\end{array}$ & $\begin{array}{c}\text { Order from } \\
\text { manufacturers }\end{array}$ & \multicolumn{3}{|c|}{ Order from manufacturers and prepare packs } \\
\hline $\begin{array}{c}\text { Role of } \\
\text { Manufacturers }\end{array}$ & $\begin{array}{l}\text { Deliver to } \\
\text { merchants }\end{array}$ & \multicolumn{3}{|c|}{ Deliver to Kitter } \\
\hline Innovation & - & Use of Kitter & $\begin{array}{c}\text { Use of an } \\
\text { information } \\
\text { system across the } \\
\text { supply chain }\end{array}$ & $\begin{array}{l}\text { Synchronised } \\
\text { lead-times across } \\
\text { the supply chain }\end{array}$ \\
\hline $\begin{array}{c}\text { Total order } \\
\text { cycle time } \\
\text { days }\end{array}$ & 21 days & 14 days & 5 days & 3 days \\
\hline
\end{tabular}

Table 2 - Summary of the re-engineering scenarios

\section{Simulation model}

We do not endeavour here to give a detailed description of the model as it is rather lengthy. A consistent lesson from any simulation study is that the effort and resource is skewed initially to the problem definition and 'real-world' understanding front end of the simulation process, as given in the previous sections, followed by a considerable effort in understanding the simulation outputs and the implications for 'real world' implementation. It is the latter that we concentrate on in the remainder of the case study description.

Several different models are used in this simulation, all of which are based on common features and on the same basic model. A structural overview of this basic model is presented in Figure 7 and is composed of six sub-systems. The exogenous demand is the construction plan defining the rate of units purchased by the end customers. This demand is inputted into the Home Builder planning and control system, where the orders and call-offs are generated,. Home Builder generates orders and call-offs which are transmitted to the merchants. The merchants use this 
information to generate their own orders, which are sent to the manufacturer. The manufacturer then decides on the appropriate production level to fulfil these orders. A production allocation system has been implemented to determine which merchant should receive which quantities of material in the case of shortages. Then construction on site can take place using the material delivered by the merchants. Finally some performance indicators are calculated to assess the model.

The underlying simulation logic is the same for all the organisations included in the structure presented in Figure 7. The logic is based on Forrester's production and distribution system (Forrester, 1958) and on the Inventory and Order Based Production Control System (IOBPCS) model (Towill, 1982). The IOBPCS model represents the rule for generating order requirements and is analogous to the classic order-up-to rule often used in inventory control systems (Lalwani et al., 2006). The IOBPCS model, first analysed by Coyle (1977), has been extensively studied by the Logistics Systems Dynamics Group at Cardiff University since 1982, following the framework outlined by Naim and Towill (1994) in Figure 1 (see Ferris and Towill, 1993; John et al., 1994; Cheema, 1994; Towill et al., 1997; Lewis, 1997; Disney et al., 2000).

Figure 8 illustrates an IOBPCS based representation of the Merchants sub-system using Vensim ${ }^{\circledR}$. The level of production required (the order rate) is based upon the level of demand which has been averaged (over a period of Ta time units) and the level of current inventory in comparison with a target inventory. Ti represents the time to adjust for the differences between the actual and target inventory levels and $T p$, the production delay.

A feature present in Forrester's (1958) original model and not previously represented in the IOBPCS was added to the IOBPCS model. Usually an IOBPCS model is linear and it is assumed that whatever is asked for will come out of the pipeline after a delay. Forrester incorporated a 
Strohhecker, S., Disney, S.M. and Naim, M.M., (2008), "Understanding supply chain dynamics via simulation", Chapter 9 in "Construction Supply Chain Management Handbook", Edited by O'Brien, W.J., Formoso, C.T., Vrijhoef, R. and London, K.A., CRC Press, Boca Raton, USA, 30pp. ISBN 978-1-4200-4745-5.

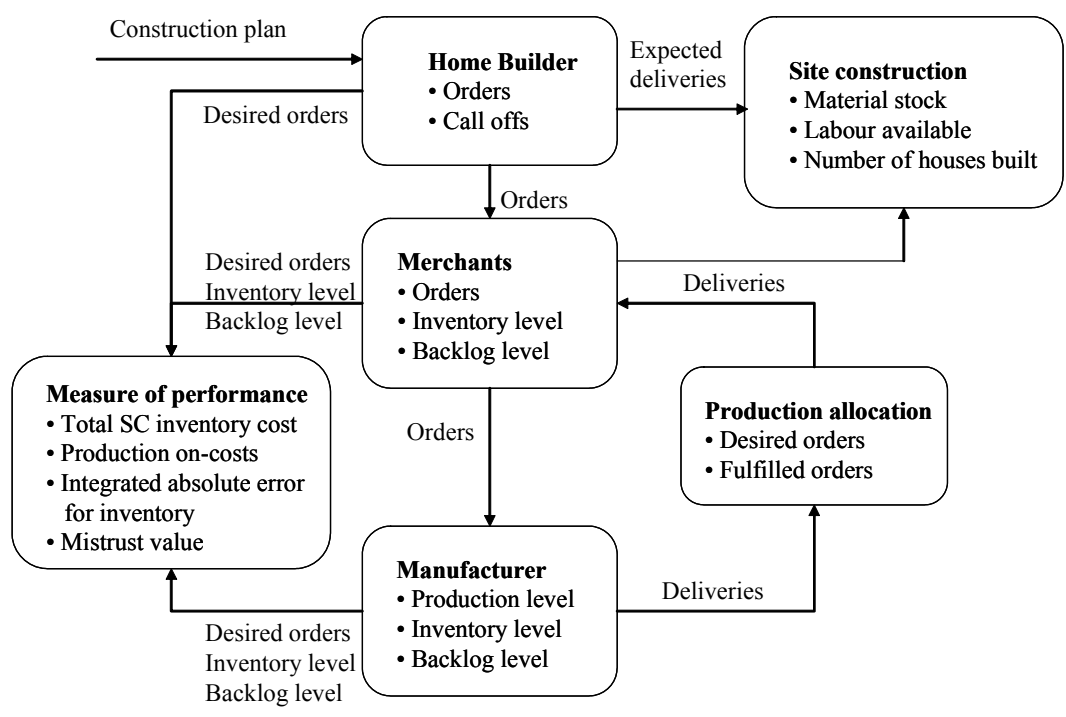

Figure 7 - Model structure overview

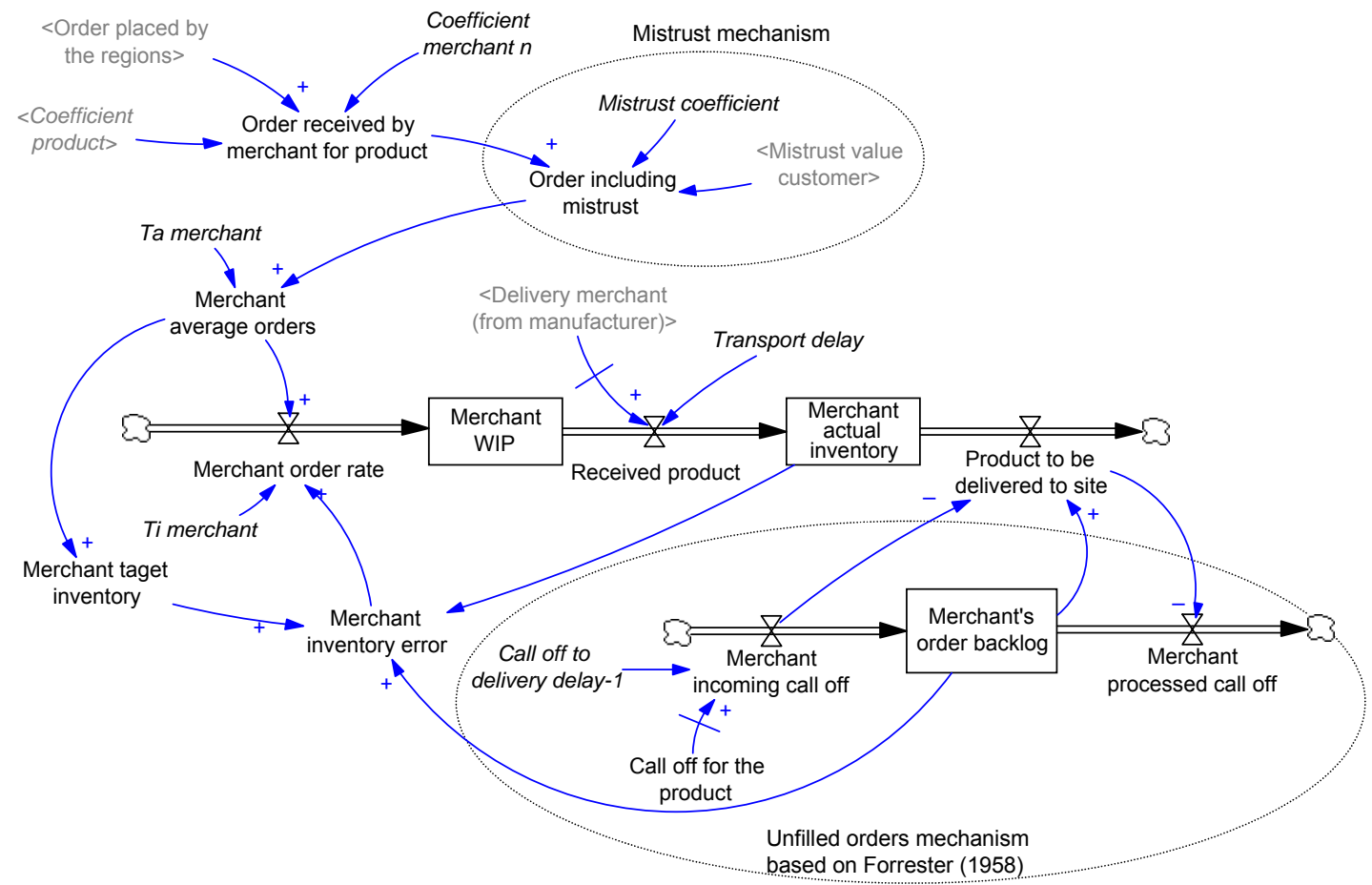

Figure 8 - Simplified stock and flow diagram for Merchants

backlog function utilising a non-linear representation. In this case, if there are no products 
available in stock, the products cannot be delivered. This feature takes into account the unfilled orders or order backlog. The order backlog is equal to the previous backlog plus new orders received less any shipments that have been made in the same period of time.

The settings of $T a$ (time to average consumption), $T i$ (time to adjust inventory) and $T p$ (the production delay) are based on John et al. (1994), Towill and Del Vecchio (1994), Mason-Jones et al. (1997) and Mason-Jones (1998). Several studies showed that in order to reduce demand amplification in IOBPCS models, a good setting would be $T a=2 T p$ and $T i=T p$ (John et al., 1994; Mason-Jones, 1998). However Towill and Del Vecchio (1994) argue different settings could be used depending on the purpose of the model and where the company is positioned in the supply chain. Therefore the settings proposed by John et al. (1994) were used for the manufacturer and those of Towill and Del Vecchio (1994) for the merchants, i.e. $T a=T i=2 T p$. A mistrust mechanism has been included in the model. The modelling of mistrust is based on real life observations during the case study and on Sterman (2000). Mistrust is understood as being the lack of trust between trading partners. Very often this lack of trust is especially tangible when customers do not receive the full quantity of what they have ordered. Instead of trusting that the supplier will deliver the missing products as soon as they become available, customers over-order to make sure that they will receive the real quantities they need. This principle has therefore been reflected in the model as follows: whenever the customers do not receive the full delivery of what they have ordered, the next order they will place will be increased by a percentage of the quantity of product undelivered An information enrichment mechanism has also been incorporated into the model and can easily be switched off. This mechanism is based on Mason-Jones's (1998) work and has been placed within the manufacturer. The information enrichment mechanism allows the manufacturer to 
utilise the smoothed market demand (merchant average orders) and the smoothed customer orders (manufacturer average orders) to decide on the production level.

For example, when there is $100 \%$ information enrichment, the manufacturer is relying solely on the market sales data from Home Builder to decide how many products to produce and could thus easily respond incorrectly to customer demand (merchants). If there is $50 \%$ information enrichment then the manufacturer will base his decision on $50 \%$ of the market demand and $50 \%$ of its customer demand. Finally setting the model to $0 \%$ information enrichment means the manufacturer relies solely on its customer demand (the merchants).

\section{Simulation model verification / validation}

Model validation and verification are also very important issues for all modellers. However, Sterman (2000) clearly states that, "no model can ever be verified or validated", as by definition they are a simplified representation of the reality and therefore vary fro $\mathrm{m}$ the real world in many different ways. Forrester and Senge (1980) add that "validation is the process of establishing confidence in the soundness and usefulness of a model. Validation begins as the model builder accumulates confidence that a model behaves plausibly and generates problem symptoms or modes of behaviour seen in the system". Furthermore a model can be considered as realistic "to the extent that it can be adequately interpreted, understood, and accepted by other points of view” (Churchman, 1973).

Solberg (1992) emphasise the benefits of simple models, stating that "the power of a model or modelling technique is a function of validity, credibility, and generality. Usually the simplest model which expresses a valid relation will be the most powerful”. Hence, models need, one way or another, to be validated, however there is no single test which would allow the modellers to assert that their models have been validated. Rather, the level of confidence in the model can 
increase gradually as the model passes more tests (Forrester and Senge, 1980).

A wide range of tests to build confidence in the model have been developed (e.g. Forrester and Senge, 1980; Barlas, 1989; Barlas, 1990; Barlas, 1996), of which Sterman (2000) presents a summary. These twelve tests are as follows:

The boundary adequacy test is concerned with the appropriateness of the model's boundary. For this test the main question to answer is if the appropriate concepts have been included in the model to address the problem. As stated previously, the aim of the model for this chapter is to compare different supply chain scenarios where a few parameters change, and assess the impact of these changes on the dynamic behaviour. The area concerned is the house building supply chain. The main players in the supply chain have been represented (i.e. Home Builder, merchants and distributor). The focus of the model is placed upon the material and information flow. Both flows have been repeatedly and successfully studied previously using a member of the IOBPCS model, also used here. Furthermore, although simplified, the model was considered as representative of the real situation by managers from the companies modelled.

The structure assessment test, as its name indicates, is concerned with the consistency of the structure of the model by verifying if the structure of the model represents the real system. As previously presented, the basis of the model is the IOBPCS models. In addition, Coyle (1977), Edghill (1990) and Berry et al (1998) asserted that the IOBPCS model was representative of production practice and replicate the dynamic behaviour of real world systems to a reasonable degree of accuracy. Finally some changes have been made to the basic IOBPCS model to take into account some real life issues such as unfulfilled orders and the distinction between orders and call offs.

The dimensional consistency test examines if the units of measures used in the model are 
consistent. This was carried out using the dimensional consistency function available in Vensim ${ }^{\circledR}$.

The parameter assessment test compares the model parameters to knowledge of the real system to determine if the parameters correspond conceptually and numerically to real life. The parameter values principally on real data collected during interviews.

The extreme condition test analyses the behaviour of the model under extreme conditions to verify that the model behaves in a realistic fashion. In the model studied in this chapter, the extreme condition test was carried out for an extremely high demand, the stock level and the amount of labour available then dropped to zero. The number of houses completed reflected the labour capacity. However, as no capacity restriction has been made in the model, the stock level still recovered using an extremely high production level. Capacity restriction was not introduced into the model so as to keep it as simple as possible, and also because the purpose of the model is not to study capacity issues but broader issues of dynamic behaviour.

The integration error test verifies if the time step utilised for the simulation and the integration method are appropriate for the purpose of the model. In the present case the time step was set at one day, however in order to test the model, the time step has been cut in half, in quarter and in eights and the results compared. For the purpose of this model, the differences were marginal. The test was also carried out using a different integration method.

The behaviour reproduction test assesses the model's ability to reproduce the behaviour of the real system. This test is generally used for a model whose purpose is to reproduce very accurately the real world system by comparing simulation results and real historical data. Although this test does not apply here and the model has already been proven to be representative of a production control system (as stated in the structure assessment test), the 
model was presented to the case company's personnel. They all agreed that it represented their supply chain.

The behaviour anomaly test, which examines the importance of specific relationships by deleting or modifying them, was utilised during the model development process. This test helped in analysing the influence of specific variables.

The family-member test asks whether a model could be used to represent other more particular models. As stated previously, the IOBPCS used in the model is already part of a model family. Furthermore, the model was used to simulate different scenarios by "switching on or off" the relevant sub-systems and therefore the model proves to be a general one, that can be adapted to represent specific members.

The surprise behaviour test is concerned with unexpected behaviour displayed by the model. The test is passed when the behaviour does indeed occur in the real world. This was the case for the build up of stock observed at the merchants and suppliers level.

When using a normal IOBPCS model, the stock first diminishes before regaining a stable state. However in the model studied here, the stock first increases and then diminishes. This is, however, happening in the real world where companies stock up in advance of a large order. Sensitivity analysis tests the robustness of the model. As the model is based on an IOBPCS model, sensitivity analysis have already been carried out and showed the robustness of the IOBPCS model (e.g. Edghill, 1990; Disney et al., 2000). However, a new sensitivity analysis has also been carried out for the overall model. The analysis took into consideration the three parameters influencing the ordering policy, i.e. $\mathrm{T}_{\mathrm{a}}$ (time to average consumption), $\mathrm{T}_{\mathrm{i}}$ (time to adjust inventory) and production delay. The analysis was carried out to study the impact of these parameters on the manufacturer order rate and the stock of products at the manufacturer level. $T_{a}$ 
was tested for a range from 1 to $60, T_{i}$ from 2 to 30 and production delay from 1 to 30 , which is the maximum range utilised during the simulations.

The validated model is then subjected to extensive dynamic analysis. The objective of this stage is to determine how the supply chain responds dynamically to various test inputs. For example, we may wish to see how the supply chain behaves to a sharp, step change in customer demand. It is at this point that the strength of simulation analysis becomes apparent as various scenarios may be adopted and evaluated relatively easily and quickly. A structured approach to exploiting the supply chain model is presented later in this chapter.

\section{Scenarios description}

The four scenarios taken into consideration are those studied in the previous sections: (a) the Baseline scenario represents the traditional low-value fit-out supply chain; (b) in the Kitter scenario the merchants are replaced by a single organisation; (c) in the Integrated Information scenario an information system is used to transfer information across the supply chain; and finally (d) in the Synchronised scenario the lead-times across the supply chain are synchronised. In the Baseline scenario, the regional buyer places the orders and the site manager calls off the material. As mentioned before, two types of product have been considered: doors and skirting boards. As several merchants are used across the country, eight have been modelled for each product, making up a total of 16 merchants. Two manufacturers have been represented, manufacturer A that produces doors, and manufacturer B that produces skirting boards. Finally, mistrust has been modelled between the agents to represent the adversarial relationships. For this scenario, mistrust was set at $100 \%$, which means that whenever the customers do not receive what they have ordered, they will increase the next order they place by $100 \%$ of the quantity of 
the product undelivered, as explained in Sterman (2000).

The Kitter scenario only models one distributor, instead of 16 different merchants. The Kitter assembles packs, which means that both doors and skirting boards need to be available to before assembling packs and delivering them to the site. As in the previous scenario, two manufacturers have been modelled. Finally, mistrust has been lowered to $75 \%$ as it was agreed with the interviewees that the relationships in this case are not fully adversarial, but a lack of trust is still present as the Kitter has only just become operational.

The Integrated Information scenario is based on the Kitter scenario but uses an information system to transfer information across the supply chain. An information enrichment mechanism, as used by Mason-Jones (1998), was implemented with an information enrichment set at 50\%. This means that the manufacturer bases its requirements $50 \%$ on the original orders placed by the regional buyer and $50 \%$ on the orders received from the Kitter. However, even though information is shared through the supply chain, it was agreed with the interviewees that mistrust should still be set at $50 \%$, as trust is slowly building up between companies but they are not yet ready to trust each other fully.

The Synchronised scenario also uses an information system, but this time it was set at $75 \%$ which, according to Mason-Jones (1998), is one of the best settings. The lead-times have been synchronised across the supply chain, which means that at each level, the total order cycle time is set at 3 days (based on the interviewees' responses). Finally, mistrust has been taken out of the model by setting it at $0 \%$, which is the equivalent of total trust between the partners. Thus, even though customers may not receive what they ordered, they trust their suppliers that missing products will be delivered as soon as possible, and therefore they do not need to over-order. The lead-times and other parameters for each scenario are given in Table 3. 


\section{Simulation results}

Each scenario has been simulated daily for a step change in demand over a period of 3 years. The

\begin{tabular}{|c|c|c|c|c|}
\hline Factor & Baseline & Kitter & $\begin{array}{c}\text { Integrated } \\
\text { Information }\end{array}$ & Synchronised \\
\hline $\begin{array}{c}\text { Order to call off } \\
\text { lead-time }\end{array}$ & 7 days & 7 days & 1 day & 1 day \\
\hline $\begin{array}{c}\text { Call off to delivery } \\
\text { lead-time }\end{array}$ & 14 days & 7 days & 4 days & 2 days \\
\hline $\begin{array}{c}\text { Order to delivery } \\
\text { from } \\
\text { Manufacturer A }\end{array}$ & 10 days & 10 days & 10 days & 3 days \\
\hline $\begin{array}{c}\text { Order to delivery } \\
\text { from } \\
\text { Manufacturer A }\end{array}$ & 7 days & 7 days & 7 days & $0 \%$ \\
\hline Mistrust & $100 \%$ & $75 \%$ & $50 \%$ & $75 \%$ \\
\hline $\begin{array}{c}\text { Information } \\
\text { enrichment }\end{array}$ & $0 \%$ & $0 \%$ & $50 \%$ & \\
\hline
\end{tabular}

Table 3 - Summary of the parameters for the four low-value fit-out scenarios

step change in demand increased from 100 to 120 houses at day 20. First of all, it is interesting to analyse the ranking of the scenarios for the step change in demand, taking into consideration the six dynamic criteria presented given in Table 4, namely:

- Peak value - it is the maximum order or production rate of a system and determines the highest capacity requirements. The peak value should be kept a low as possible

- Peak time - indicates how quick the peak is reached and it is an indication of the speed of response of the system. The peak time should be as short as possible

- Order recovery - expresses how well our production system is doing at tracking real demand in steady state. If our system never 'catches up' with demand then we are always in backlog, thus smaller order recovery times are desirable

- Stock depletion - expresses how far stock levels deplete and it is a surrogate for the risk of stocking out. This depletion should be kept as small as possible 
- Trough time - the time to reach the maximum stock depletion and again indicates how fast we respond to changes in demand. The trough time should be kept as small as possible

- Stock recovery - indicates how long it takes for the stock level to recover following a step change in demand. Systems that recover quicker are better then systems that take a long time to recover.

Using a linear scale, where four stars is the best and one star the worst, the results presented in Table 4 represent the response at manufacturer level. For ease of presentation, only the door manufacturer response is presented. Synchronised scenario achieves the best overall performance, followed by Baseline scenario. The Integrated Information scenario achieves the worst performance for peak value. In contrast, the Synchronised scenario registers the worst performance for stock depletion, while achieving the best performance for peak time and trough time due to the short lead-times.

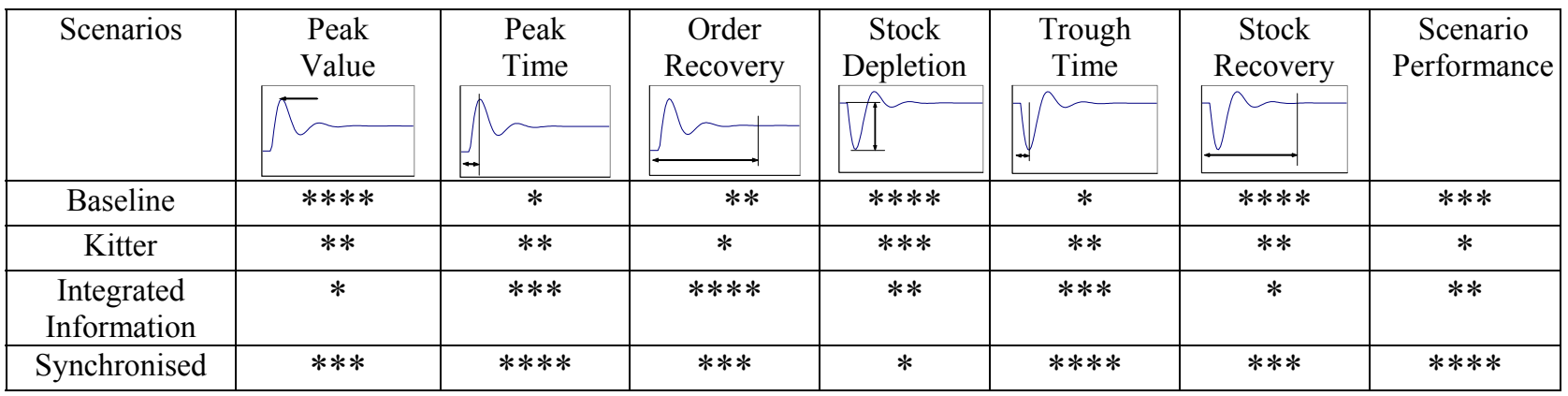

Note: $* * * *$ represents the best performance and $*$ the worst

Table 4 - Ranking of the different scenarios for dynamical performance criteria at the manufacturers for step change in the demand

The dynamic performance, assessed using the six criteria above, can be summarised using only two criteria. These are the,

1. production on-costs - based on the cumulative absolute error between a given behaviour 
and the actual behaviour. Hence the order rate is compared with the actual end-customer orders and after having integrated the absolute error, the result is cubed so as to give the production on-costs (Wikner et al., 1991).

2. the manufacturer's inventory deviations - calculated for the actual inventory level and is based on the same principle as for the production on-costs. The area considered is the difference between the actual inventory level and the target inventory..

Furthermore, the total supply chain inventory costs can be simply calculated based on the total inventory holdings over the period of simulation. These criteria have been calculated using the simulations. Table 5 presents the ranking of the scenarios using these three performance criteria.

\begin{tabular}{|c|c|c|c|c|}
\hline Scenarios & $\begin{array}{c}\text { Production on- } \\
\text { costs }\end{array}$ & $\begin{array}{c}\text { Manufacturer's } \\
\text { inventory } \\
\text { deviations }\end{array}$ & $\begin{array}{c}\text { Total SC } \\
\text { inventory costs }\end{array}$ & $\begin{array}{c}\text { Scenario } \\
\text { performance }\end{array}$ \\
\hline Baseline & $* * *$ & $* * * *$ & $*$ & $* * *$ \\
\hline Kitter & $*$ & $* *$ & $* * * *$ & $* * * *$ \\
\hline $\begin{array}{c}\text { Integrated } \\
\text { Information }\end{array}$ & $* *$ & $* * *$ & $* * *$ & $* * *$ \\
\hline Synchronised & $* * * *$ & $*$ & $* *$ \\
\hline
\end{tabular}

Note: $* * * *$ represents the best performance and $*$ the worst

\section{Table 5 - Scenarios' ranking for a step change in demand}

The production on-costs are minimised in the case of Synchronised scenario, which means that Synchronised scenario achieves the smallest demand amplification among the four scenarios. The Baseline scenario registers the worst results in terms of total supply chain inventory costs. It could be suggested that this is due to the large number of merchants. However, the stock level for each merchant was set to at least four times the average demand, knowing that the total demand placed on the merchants is the same as for Kitter. 
In order to improve the understanding of the above results, the magnitude of the impact that each scenario has on performance needs to be studied. A comparison of each scenarios in relation to the Baseline scenario is presented in Table 6 . It can be seen that the total supply chain inventory costs are reduced for all three scenarios. Furthermore the Synchronised scenario improves the production on-costs by $30 \%$ in comparison with baseline scenario. Finally, all three scenarios increase the inventory deviation in comparison with Baseline scenario, especially Synchronised scenario with a $16 \%$ increase.

The results of the four strategies for a step change in demand have been analysed. However, the impact of each SCM principle cannot be fully understood as more than one parameter has been changed in each scenario. Therefore further simulations have been carried out to analyse the

\begin{tabular}{|c|c|c|c|}
\hline Scenarios & Production on-costs & $\begin{array}{c}\text { Manufacturer's } \\
\text { inventory deviations }\end{array}$ & Total SC inventory \\
\hline Kitter & $+22 \%$ & $+10 \%$ & $-0.8 \%$ \\
\hline $\begin{array}{c}\text { Integrated } \\
\text { Information }\end{array}$ & $+21 \%$ & $+6 \%$ & $-1.1 \%$ \\
\hline Synchronised & $-30 \%$ & $+16 \%$ & $-0.8 \%$ \\
\hline
\end{tabular}

Table 6 - Impact of the scenarios on performance criteria in comparison with Baseline scenario for a step change in demand

impact of every single change made to move from one scenario to the next.

The first comparison has been carried out between the Baseline scenario and the Kitter scenario. The SCM principles implemented in this comparison were: centralisation of supply, the total cycle time reduction and improved relationships between the trading partners. This was simulated by:

- "No merchant" strategy: replacing the merchants by the Kitter;

- "Delay call off" strategy: reducing the lead-time from order to call off from 14 to 7 days;

- "From stock" strategy: taking material out of stock earlier, in order to assemble packs, from 1 to 8 days; 
- "Mistrust customer" strategy: reducing the mistrust level between the regional buyer and the merchants from $100 \%$ to $75 \%$; and

- "Mistrust merchants" strategy: reducing the mistrust level between the merchants and the manufacturers from $100 \%$ to $75 \%$.

Table 7 presents the amplitude of impact that each strategy has in comparison with Baseline scenario. "No merchant" strategy improves both production on-costs (by 38\%) and the manufacturers inventory deviations (by 11\%). This means that it improves the dynamic behaviour of the supply chain. Therefore, moving away from multiple merchants on a regional basis and choosing one single company on a national basis not only improves the dynamic performance but also reduces the total supply chain inventory costs. This confirms Charatan's (1999) observation that centralisation on a national basis of supply has almost always been beneficial. However, reducing the lead-time between order and call-off has a negative impact on the dynamic behaviour. This is understandable as the advance notice of what is going to be called off is shorter and therefore manufacturers have less time to react to changes in demand. In a similar manner, "From stock" strategy worsens the dynamic behaviour as materials are taken from stock earlier on and thus the manufacturers do not have much time to build up their stock against the increase in demand. All three strategies ("No merchant", "Delay call off", and "From stock") reduce the total supply chain inventory costs.

\begin{tabular}{|c|c|c|c|}
\hline Scenarios & Production on-costs & $\begin{array}{c}\text { Manufacturer's } \\
\text { inventory deviations }\end{array}$ & $\begin{array}{c}\text { Total SC inventory } \\
\text { costs }\end{array}$ \\
\hline No merchants & $-38 \%$ & $-11 \%$ & $-0.2 \%$ \\
\hline Delay call off & $+65 \%$ & $+14 \%$ & $-0.2 \%$ \\
\hline From stock & $+77 \%$ & $+17 \%$ & $-0.2 \%$ \\
\hline Mistrust Customer & $(-1 \%)$ & $(-0.2 \%)$ & $(+0.001 \%)$ \\
\hline Mistrust Merchants & $(-0.01 \%)$ & $(+0.3 \%)$ & $(-0.001 \%)$ \\
\hline Kitter & $+22 \%$ & $+10 \%$ & $-0.8 \%$ \\
\hline
\end{tabular}

Table 7 - Impact of each strategy from Baseline scenario to Kitter scenario 
Finally, the impact of "Mistrust" strategies is indicated in brackets as it only has a marginal impact. Furthermore it does not have the same level of safety stock as other scenarios. However it gives an interesting insight into the way in which the increase of trust between trading partners affects performance. Interestingly, "Mistrust customer" increases the total supply chain inventory costs, while "Mistrust merchants" reduces it. Therefore, when the level of mistrust is reduced between the site and the merchants, the total supply chain inventory costs increase, while the dynamic performance at the manufacturer level improves. This can be explained by the fact that there is less disturbance or noise in the demand signal received by the manufacturers.

The reduction of mistrust between merchants and manufacturers improves the production oncosts but increases the manufacturer's inventory deviations. This can be explained by the fact that as mistrust diminishes, the demand received by the manufacturer is lower (only $75 \%$ of the product quantities that have not been received is added to the demand instead of $100 \%$ ). However, it also means that the manufacturer does not overproduce and its stock level diminishes more rapidly.

The Kitter and Integrated Information scenarios were also compared. The SCM principles implemented in this comparison were: the use of an information system to share end-customer demand, reduction of total cycle time, and improved relationships between trading partners. These principles were implemented by (again, introducing the strategies one at a time):

- "Information enrichment" strategy: passing on the site demand to the manufacturers. The manufacturers based their requirements $50 \%$ on the site demand and $50 \%$ on the orders received from Kitter;

- $\quad$ "Delay call off" strategy: reducing the lead-time from order to call off from 7 days to 1; 
- "Mistrust customer" strategy: reducing the mistrust level between the regional buyer and Kitter from $75 \%$ to $50 \%$; and

- "Mistrust Kitter" strategy: reducing the mistrust level between Kitter and the manufacturers from $75 \%$ to $50 \%$.

As presented by Mason-Jones (1998), the implementation of an information enrichment mechanism improves the dynamic behaviour of the supply chain. It also reduces the total supply chain inventory costs. As seen previously, the "Order to call off" strategy has a negative impact on the dynamic behaviour (by increasing both production on-costs and the manufacturer's inventory deviations), but improves the total supply chain inventory costs.

Again, by reducing the mistrust level from 75 to $50 \%$ the total supply chain inventory costs are increased (Table 8). The marginal increase of the manufacturers inventory because of "customer Mistrust" is due to a greater drop in inventory level in the case of $50 \%$ mistrust. However as there are fewer disturbances in the demand signal, the inventory level recovers more rapidly. The increase in production on-costs for the "Mistrust Kitter" strategy is explained by the fact that the production level peaks higher than for $75 \%$ mistrust. The marginal reduction of manufacturer's inventory deviations for inventory is due to a smaller trough in inventory levels.

\begin{tabular}{|c|c|c|c|}
\hline Scenarios & Production on-costs & $\begin{array}{c}\text { Manufacturer's } \\
\text { inventory deviations }\end{array}$ & $\begin{array}{c}\text { Total SC inventory } \\
\text { costs }\end{array}$ \\
\hline $\begin{array}{c}\text { Information } \\
\text { Enrichment }\end{array}$ & $-21 \%$ & $-13 \%$ & $-0.1 \%$ \\
\hline Order to call off & $+13 \%$ & $+8 \%$ & $-0.2 \%$ \\
\hline Mistrust Customer & $(-4 \%)$ & $(+0.1 \%)$ & $(+0.1 \%)$ \\
\hline Mistrust Kitter & $(+0.1 \%)$ & $(-2 \%)$ & $(+0.01 \%)$ \\
\hline $\begin{array}{c}\text { Integrated } \\
\text { Information }\end{array}$ & $-1 \%$ & $-3 \%$ & $-0.4 \%$ \\
\hline
\end{tabular}

Table 8 - Impact of each strategy from Integrated Information scenario to Synchronised scenario 


\section{Summary of the simulation results}

Several important lessons were learnt from this simulation study. First of all, Integrated Information scenario achieves the best overall performance for a step change in demand. All three scenarios - Kitter, Integrated Information, and Synchronised - improve the total supply chain inventory costs in comparison with Baseline scenario.

Using one single national merchant instead of several regional merchants improves all three performance criteria (production on-costs, manufacturers' inventory deviations and total supply chain inventory costs). This is supported by Charatan's (1999) and Henkoff's (1994) observations on the positive impact of centralisation of supply. Reducing the delay between placing an order and the call-off has a negative impact on dynamic performance. This is also the case for the "From stock" strategy, which takes material out of stock several days before delivery.

Information enrichment improves the performance criteria studied, as generically postulated by Mason-Jones (1998), whilst reducing manufacturing lead-times, whilst keeping the parameters in the ordering rule constant, has a detrimental effect on both the total supply chain and the manufacturer's inventory costs. However, it has a positive effect on production on-costs. Finally, reducing mistrust either between customer and merchants/Kitter, or between merchants/Kitter and manufacturers, has a positive effect in terms of faster recovery to a stable state. However, in all cases, reduction of the mistrust level between trading partners increases the total supply chain inventory costs.

\section{Discussion}

A low-value fit-out supply chain has been studied in this chapter. First of all, an analysis of the 
current state was undertaken. Seven "hot spots" were identified as being the major problems of the traditional low-value fit-out supply chain. In order to address these "hot spots", three steps were identified with the ultimate aim of improving performance. The first step is to move away from regional supply using multiple merchants to a single national supplier, who can also prepare the materials in packages to reduce the number of deliveries and wastage on-site. As seen during the simulations, this scenario reduces total supply chain costs but it has a negative effect on the dynamic behaviour.

The second step is to use customer information across the supply chain through an information enrichment mechanism. This not only reduced total order cycle time but also improved the dynamics of the supply chain. Finally, the last step is to synchronise lead-times across the supply chain. Here again, total supply chain inventory costs can be reduced and total ordering cycle time reduced.

Simulation has shown us that centralising the supply (No merchants strategy) generally has a positive effect, improving dynamic behaviour and reducing total supply chain inventory costs, as identified by Charatan (1999) in the retail sector. The reduction of the delay between placing the order and calling-off, or in other words, advance notice given to suppliers, has a detrimental effect on the dynamics of the models. It was confirmed that using the information enrichment strategy improves performance, while reducing the levels of mistrust between trading partners helps the system to return faster to a stable state.

\section{Conclusions}

The summary of the performance results for the four scenarios is presented in Table 9. The main benefit of the simulation was to demonstrate to managers the long-term implications of the 
dynamic behaviour of various supply chain designs. With the simulation we were also able to investigate the trade-offs and scenarios in a safe environment.

\begin{tabular}{|c|c|c|c|c|c|}
\hline & KPI's & $\begin{array}{l}\text { Traditional low } \\
\text { value fit out } \\
\text { supply chain }\end{array}$ & $\begin{array}{l}\text { Kitter's low } \\
\text { value fit out } \\
\text { supply chain } \\
\end{array}$ & $\begin{array}{c}\text { Integrated information } \\
\text { for the low value fit out } \\
\text { supply chain }\end{array}$ & $\begin{array}{l}\text { Synchronised } \\
\text { low value fit out } \\
\text { supply chain }\end{array}$ \\
\hline \multirow{4}{*}{$\sum_{\infty}^{\infty}$} & Stock levels & $80 *$ & $126^{*}$ & $132 *$ & $155^{*}$ \\
\hline & $\begin{array}{c}\text { Total order cycle } \\
\text { time }\end{array}$ & 21 days & 14 days & 5 days & 3 days \\
\hline & Inventory costs & $£ 1.037 \mathrm{M}^{*}$ & $£ 1.029 \mathrm{M}^{*}$ & $£ 1.025 \mathrm{M}$ & $£ 1.029 \mathrm{M}$ \\
\hline & $\begin{array}{l}\text { Customer } \\
\text { satisfaction }\end{array}$ & $\begin{array}{l}\text { Low (Home } \\
\text { Builder) }\end{array}$ & $\begin{array}{l}\text { Medium (House } \\
\text { Builder) }\end{array}$ & $\begin{array}{l}\text { Medium-High (House } \\
\text { Builder) }\end{array}$ & $\begin{array}{l}\text { High (House } \\
\text { Builder) }\end{array}$ \\
\hline \multirow{4}{*}{ 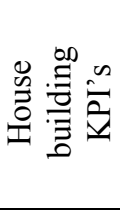 } & (Product and service) & Low (customer) & $\begin{array}{c}\text { Medium } \\
\text { (customer) }\end{array}$ & High (customer) & High (customer) \\
\hline & Product quality & Low & High & High & High \\
\hline & Predictability costs & Low & Medium & Medium-High & High \\
\hline & Predictability time & Low & Medium & Medium-High & High \\
\hline \multirow{6}{*}{ 逽吕 } & Peak value & $132 *$ & $137 *$ & $137^{*}$ & $136^{*}$ \\
\hline & Peak time & $70 *$ & $60 *$ & $58 *$ & $52 *$ \\
\hline & Order recovery & $302 *$ & $313 *$ & $280^{*}$ & $285 *$ \\
\hline & Stock depletion & $80 *$ & $126^{*}$ & $132 *$ & $155^{*}$ \\
\hline & Trough time & $59 *$ & $54 *$ & $53 *$ & $46^{*}$ \\
\hline & Stock recovery & $283^{*}$ & $348 *$ & $374 *$ & $342 *$ \\
\hline
\end{tabular}

$*$ indicates relative values from the simulations

Table 9 - Overall performance for the four different scenarios

Finally, we have described, via a case study, a method for undertaking a simulation based

business diagnostic. Notably, we have not focussed on the 'software' aspects of the simulation approach but on the pre-simulation data collection (including variables, parameters and cause and effect relationships), simulation analysis and post-simulation managerial interpretation. We were also able to verify some generic supply chain management principles in a specific supply chain setting and provide advice on how the company may exploit the newly introduced IT system. 


\section{References}

AbouRizk, S. and Halpin, D. (1990) "Probabilistic simulation studies for repetitive construction processes”, Journal of Construction Engineering and Management, Vol. 116 No. 4, pp. 575-94.

Agapiou, A., R. Flanagan, G. Norman and D. Notman (1998). "The changing role of builders merchants in the construction supply chain." Construction Management and Economics 16: $251-361$.

Anon (1998). "Merchants of bloom take the lion's share." Construction News June 11: 24-25.

Arrow, K. J., (2002). "The genesis of “optimal inventory policy"”, Operations Research, Vol. 50, No. 1, pp 1-2.

Axsäter, S., (1985). "Control theory concepts in production and inventory control”, International Journal of Systems Science, Vol. 16, No. 2., pp161-169.

Barker, R., Hong-Minh, S. and Naim, M. M. (2000). “The Terrain Scanning Methodology: Assessing and Improving Construction Supply Chains”, European Journal of Purchasing and Supply Management: Special Issue on Construction Supply Chains, Vol.6, No.3-5, pp $179-193$

Barlas, Y. (1989). "Multiple test for validation of system dynamics type of simulation models." European Journal of Operation Research 42(1): 59-87.

Barlas, Y. (1990). “An autocorrelation function-test for output validation.” Simulation 55(1): 716.

Barlas, Y. (1996). "Formal aspects of model validity and validation in system dynamics." System Dynamics Review 12(3): 183-210.

Berry, D., Evans, G. N. and Naim, M. M. (1998) "Pipeline information survey: a UK 
perspective", International Journal of Management Science, OMEGA, Vol. 26, No. 1, pp $115-132$

Bowersox, D. J., D. J. Closs and O. Helferich (1986). "Logistical management - A systems integration of physical distribution, manufacturing support and materials procurement". USA, MacMillian Publishing.

Bozer, Y. A. and L. F. McGinnis (1984). Kitting: a generic descriptive model. MHRC-tr-84-04, Georgia Institute of Technology, Atlanta, Georgia.

Burns, J.F. and Sivazlian, B.D., (1978). "Dynamic analysis of multi-echelon supply systems", Computers and Industrial Engineering, Vol. 2, pp 181-193.

Cachon, G. and Fisher, M., (1997). “Campbell soup's continuous replenishment program: evaluation and enhanced inventory decision rules", Production and Operations Management, Vol. 6, No.3, pp266-276.

Charatan, A. (1999). Retail supply chain integration. Global logistics and distribution planning Strategies for management. D. Waters, CRC Press, Kogan Page: 155-172.

Checkland, P. (1981). Systems Thinking, Systems Practice. Chichester, John Wiley \&

Checkland, P. and J. Scholes (1990). Soft Systems Methodology in action. Chichester, Cheema, P., (1994). "Dynamic analysis of an inventory and production control system with an a adaptive leadtime estimator". Cardiff University. $\mathrm{PhD}$ Thesis.

Chen, F., Drezner, Z., Ryan, J.K. and Simchi-Levi, D., (2000). “Quantifying the Bullwhip effect in a simple supply chain: The impact of forecasting, lead-times and information", Management Science, Vol. 46, No. 3, pp 436-443.

Churchman, C. (1973). "Reliability of models in the social sciences", Interfaces Vol. 4, No. 1, pp. 1-12. 
Coyle, R.G., (1982). "Assessing the controllability of a production and raw materials system”, IEEE Transactions on Systems, Man and Cybernetics, Vol. SMC-12, No. 6, November/December, pp 867-876.

Disney, S.M., (2001). “The production and inventory control problem in Vendor Managed Inventory supply chains”, PhD Thesis, Cardiff Business School, Cardiff University, UK. Disney, S.M., Naim M.M., and Towill, D.R., (2000). "Generic algorithm optimisation of a class of inventory control systems", International Journal of Production Economics, Vol. 68, No. 3, pp 259-278

Disney, S.M. and Towill, D.R., (2003) "On the bullwhip and inventory variance produced by an ordering policy”, OMEGA: The International Journal of Management Science, Vol. 31, No. 3, pp157-167.

Edghill, J. (1990). "The application of aggregate industrial dynamics techniques to manufacturing systems". Cardiff University. PhD Thesis.

Edghill, J.S. and Towill, D.R., (1989). "The use of systems dynamics in manufacturing systems", Trans Inst MC, Vol. 11, No. 4, pp 208-216.

Ferris, J. S. and D. R. Towill (1993). "Benchmarking of a generic family of dynamic manufacturing ordering and control models.” Journal of Systems Engineering Vol. 3, pp. $170-182$

Forrester, J., (1961). "Industrial dynamics”, Cambridge MA, MIT Press.

Forrester, J., (1958). “Industrial Dynamics: a Major Breakthrough for Decision Makers”, Harvard Business Review, vol.36, No.4, pp 37-66.

Forrester, J. W. and P. M. Senge (1980). Test for building confidence in system dynamics models. System Dynamics. A. A. Legasto and J. W. Forrester. Amsterdam, North-Holland: 
209-228

González, V., Alarcón, L. F. and Gazmuri, P. (2006) “Design of work in process buffers in repetitive building projects: a case study", Proceedings of IGLC-14, 25-27 July 2006, Santiago, Chile, pp. 165-176.

Henkoff, R. (1994). "Delivering the goods.” Fortune November 28: 64-78.

Hoover, S. and R. Perry (1989). “Simulation - A problem-solving approach”. USA, AddisonWesley.

Johansson, M. I. (1991). "Kitting systems for small parts in manual assembly systems”. London, Taylor \& Francis.

John, S., M. Naim and D. Towill (1994). "Dynamic analysis of a WIP compensated decision support system.” International Journal of Manufacturing System Design Vol. 1, No. 4, pp 283-297.

Johnsson, M. (1992). “Discrete event simulation, an evaluation tool for logistic systems”. Lund, Sweden, Lund Institute of Technology.

Kamata, V. R. and Martinez, J. C. (in press) "Generic representation of 3D motion paths in dynamic animations of simulated construction processes", Automation in Construction

Kramer, N. and J. de Smit (1977) "Systems thinking - Concepts and notions". Leiden, the Netherlands, Stenfert Kroese, Martinus Nijhoff Social Sciences Divisions.

Lalwani, C.S., Disney, S.M. and Towill, D.R., (2006) "Observable and controllable state space representations of a generalized Order-Up-To policy", International Journal of Production Economics, Vol. 101, No. 1, pp173-184

Lambrecht, M.R. and Dejonckheere, J., “A Bullwhip Effect explorer”, Research Report 9910, Department of Applied Economics, Katholieke Universiteit, Leuven, Belgium, 1999a. 
Lambrecht, M.R. and Dejonckheere, J., (1999b). "Extending the Beer Game to include real-life supply chain characteristics”, Proc. EUROMA Int. Conf. On Managing Operations Networks, pp 237-243.

Law, A. and W. Kelton (1991). "Simulation modeling \& analysis”. USA, McGraw-Hill.

Lee, H.L., So, K.C. and Tang, C.S., (2000). "The value of information sharing in a two-level supply chain”, Management Science, Vol. 46, No. 5, pp626-643.

Lewis, J. (1997). “An integrated approach to re-engineering material flow within a seamless supply chain". Cardiff University. PhD Thesis.

Lewis, J., Naim, M., Wardle, S. and Williams, E., (1998). “Quick Scan your way to supply chain improvement”, Institute of Operations Management, Control, Vol. 24, No. 5, pp 14-16.

Martinez, J. C. and Ioannou, P. G. (1999) "General-Purpose Systems for Effective Construction Simulation”, Journal of Construction Engineering and Management, Vol. 125, No. 4, pp. $265-276$

Mason-Jones, R. (1998). "The holistic strategy of market information enrichment through the supply chain". Cardiff. University PhD Thesis. Cardiff

Mason-Jones, R., Naim, M,. and Towill, D., (1997). "The impact of pipeline control on supply chain dynamics.” The International Journal of Logistics Management, Vol. 8, No. 2, pp. $47-62$.

Mason-Jones, R. and D. Towill (1998). "Shrinking the Supply Chain Uncertainty Circle." Control, Vol. 24, No. 7, pp. 17-22.

Naim, M. M. and Barlow, J., (2003), “An innovative supply chain strategy for customised housing", Construction Management and Economics, Vol. 21, pp 593-602

Naim, M. M., Childerhouse, P., Disney, S. M. and Towill, D.R., (2002). “A supply chain 
diagnostic methodology: determining the vector of change", Computers \& Industrial Engineering: An International Journal, Vol. 43, No. 1-2, pp 135-157

Naim, M., Disney, S. and Towill, D., (2004). "Supply chain dynamics”, in Understanding supply chains: concepts, critiques and futures, edited by Steve New and Roy Westbrook, Oxford University Press, pp 109-132.

Naim, M.M. and Towill, D.R., (1994). "Establishing a framework for effective materials logistics management”, International Journal of Logistics Management, Vol. 5, No. 1, pp $81-88$

Nassara, K, Thabetb, W. and Beliveauc, Y. (2003) "Simulation of asphalt paving operations under lane closure conditions", Automation in Construction, Vol. 12, No. 5, pp. 527-541

Naylor, T., J. Balintfy, D. Burdick and C. Kong (1966). "Computer simulation techniques". USA, John Wiley.

Popplewell, K. and Bonney, M. C., (1987). “The application of discrete linear control theory to the analysis of multi-product, multi-level production control systems", International Journal of Production Research, Vol. 25, No. 1, pp 45-56.

Sabath, R. (1995). "Volatile demand calls for quick response: the integrated supply chain." Logistics Information Management 8(2): 49-52.

Simon, H.A., (1952). "On the application of servomechanism theory to the study of production control", Econometrica, Vol. 20, pp. 247-268.

Solberg, J. (1992). "The power of simple models in manufacturing. Manufacturing systems Foundations of World-Class Practice”. J. Hein and W. Compton. Washington, USA National Academy of Engineering Press, pp. 215-223.

Sterman, J. (2000). Business Dynamics - Systems Thinking and Modelling for Complex World. 
Boston, McGraw-Hill Higher Education.

Sterman, J., (1989). "Modelling managerial behaviour: Misperceptions of feedback in a dynamic decision making experiment”, Management Science, Vol. 35, No. 3, pp. 321-339.

Stevens, G. (1989). "Integrating the supply chain”, International Journal of Physical Distribution and Logistics Management 19(8): 3-8.

Towill, D. R. (1982). "Dynamic analysis of an inventory and order based production control system.” International Journal of Production Research, Vol. 20, No. 6, pp. 671-687

Towill, D. (2000). "A route map for substantially improving supply chain dynamics." International Journal of Manufacturing Technology and Management, Vol. 1, No. 1, pp. 94-111.

Towill, D. and Del Vecchio, A., (1994). "The application of the filter theory the study of supply chain dynamics." Production Planning \& Control, Vol. 5, No. 1, pp. 82-96.

Towill, D., Evans, G. and Cheema, P. (1997). “Analysis and design of an adaptive minimum reasonable inventory control system.” International Journal of Production Planning and Control 8(6): 545-557.

Towill, D.R., Lambrecht, M. R., Disney, S. M. and Dejonckheere, J., (2003). “Explicit filters and supply chain design”, Journal of Purchasing \& Supply Management, Vol. 31, Issue 2, pp.73-81.

van Ackere, A., Larsen, E.R. and Morecroft, J.D.W., "Systems thinking and business process redesign: An application to the Beer Game", European Management Journal, Vol. 11, No. 4, 1993, pp412-423.

Vassian H.J., (1955). "Application of discrete variable servo theory to inventory control”, Journal of the Operations Research Society of America, Vol. 3, No. 3, pp272-282. 
Waller, M., Johnson, M.E. and Davis, T., (1999). "Vendor managed inventory in the retail supply chain”, Journal of Business Logistics, Vol. 20, No. 1, pp183-203.

Warburton, R. and Disney, S.M., (2007), "Variance Amplification: The Equivalence of Discrete and Continuous", Forthcoming in the International Journal of Production Economics.

Wegelius-Lehtonen, T. and S. Pahkala (1998). "Developing material delivery processes in cooperation - An application example of the construction industry.” International Journal of Production Economics 56-57: 689-698.

Wikner, J., Towill, D.R. and Naim, M.M. (1991) "Smoothing Supply Chain Dynamics", International Journal of Production Economics, Vol. 22, pp 231-248

Wolstenholme, E. F. (1990) System enquiry: a system dynamics approach. Chichester, Wiley.

Sterman, J. (2000). Business Dynamics - Systems Thinking and Modelling for Complex World. Boston, McGraw-Hill Higher Education. 